\title{
Detection of Counterfeit Tequila by Fluorescence Spectroscopy
}

\author{
José Manuel de la Rosa Vázquez, Diego Adrián Fabila-Bustos, \\ Luis Felipe de Jesús Quintanar-Hernández, Alma Valor, and Suren Stolik
}

Laboratorio de Láseres, ESIME ZAC, Instituto Politécnico Nacional, 07738 México, DF, Mexico

Correspondence should be addressed to José Manuel de la Rosa Vázquez; mdelaros@ipn.mx

Received 22 July 2015; Accepted 20 September 2015

Academic Editor: Jau-Wern Chiou

Copyright (C) 2015 José Manuel de la Rosa Vázquez et al. This is an open access article distributed under the Creative Commons Attribution License, which permits unrestricted use, distribution, and reproduction in any medium, provided the original work is properly cited.

An ultraviolet (UV) light induced fluorescence study to discriminate fake tequila from genuine ones is presented. A portable homemade system based on four light emitting diodes (LEDs) from 255 to $405 \mathrm{~nm}$ and a miniature spectrometer was used. It has been shown that unlike fake and silver tequila, which produce weak fluorescence signal, genuine mixed, rested, and aged tequilas show high fluorescence emission in the range from 400 to $750 \mathrm{~nm}$. The fluorescence intensity grows with aging in $100 \%$ agave tequila. Such fluorescence differences can even be observed with naked eyes. The presented results demonstrate that the fluorescence measurement could be a good method to detect counterfeit tequila.

\section{Introduction}

Distilled spirits adulteration with water, ethanol, or methanol is a serious economical and health problem [1]. Tequila is a very popular Mexican spirit. Its legal production reached 253 million liters in 2012 [2]. In Mexico, there are around 150 agave species whose principal use lies in the distilled alcoholic beverages production such as tequila, mezcal, sotol, and Bacanora [3]. Here we present the fluorescence spectroscopic study of original tequilas and of counterfeit ones which were obtained in the informal market in Mexico.

Different alcoholic distilled beverages, like whiskey, gin, cognac, and rum, have similar components. They also have some common sensory characteristics, mainly related to the fermentation and aging processes, but some especial and distinct compounds generally define the unique aroma of each spirit. Tequila has an aroma profile composed of smoke, almond, varnish, coffee, caramel, rancid coconut, and wet straw. It also has a lightly flowery aroma and a piquant tone in taste. These properties are not present in the aforementioned beverages. On the other hand, like whiskey, tequila shows fresh fruit, dried fruit, and fruit aromas. Also, it shows vanilla and woody aromas like rum. However, not many of other aromas found in the distilled beverages are present in tequila [4].
The manufacturing process of tequila involves harvesting the "piña," the stem of the agave plant with leaves removed, followed by cooking in an oven to convert polysaccharides (inulins) to a mixture principally of fructose and glucose. Sugars are extracted by milling and pressing and then they are fermented with yeast, typically Saccharomyces cerevisiae, in vats (often with up to $49 \%$ sugar added from sources such as cane and sorghum). The fermented mash is then doubly distilled and the finished product is diluted to obtain an alcohol content usually in the range of 35 to $55 \mathrm{vol} . \%$. The final product is colorless, though many of the premium tequilas are aged in oak vats, which result in an acquired pale to golden yellow color [5].

Two categories of tequila are very well distinguished: "100\% agave" and "mixed." For the "100\% agave" only pure blue Weber agave juice is used to be fermented and distilled. Mexican regulations rule that this kind of tequila should be produced and bottled only in a specific region of Mexico. Mixed tequila is manufactured with $51 \%$ of agave sugar adding up to $49 \%(\mathrm{w} / \mathrm{v})$ of different sugar, typically from sugar cane [6]. The mixed tequila is normally shipped out in bulk containers for bottling and sale abroad.

The Mexican Official Standard for Tequila accepts the following ranges of physicochemical specifications: 35 to 55 vol. $\%$ of ethanol; 50 to $500 \mathrm{mg} / 100 \mathrm{~mL}$ higher alcohols 


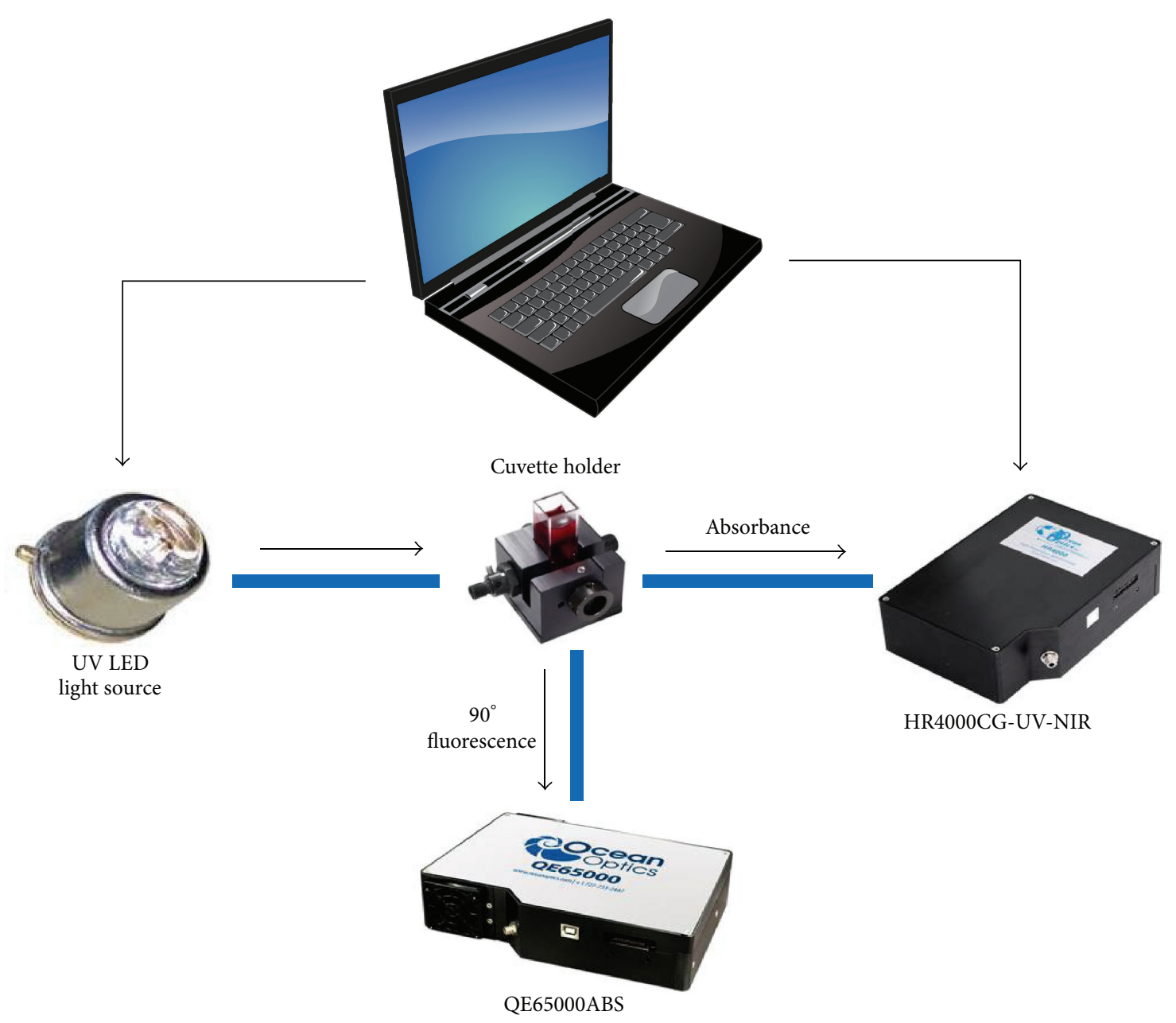

FIGURE 1: Experimental arrangement.

(referred to as pure ethanol); 30 to $300 \mathrm{mg} / 100 \mathrm{~mL}$ of methanol; 0 to $40 \mathrm{mg} / 100 \mathrm{~mL}$ of aldehydes; 2 to $250 \mathrm{mg} / 100 \mathrm{~mL}$ of esters; and 0 to $4 \mathrm{mg} / 100 \mathrm{~mL}$ of furfural [6].

Different techniques have been used for the analysis of adulterants in alcoholic beverages. Near-infrared spectrometry $[7,8]$, high-resolution gas chromatography, and stable isotope ratio analysis have been proposed for the authentication of tequilas $[9,10]$. Ultraviolet and visible (UVVIS) absorption spectroscopy has shown that tequila has an absorption band from 250 to $400 \mathrm{~nm}$, which has been used to identify adulterate and fake tequilas [11, 12]. Also, UV fluorescence of tequila induced at $337 \mathrm{~nm}$ has been measured [13]. On the other hand, UV fluorescence method has been reported to classify brandy and wine distillates [14].

This study presents the fluorescence spectra produced at four excitation wavelengths $(255,330,365$, and $405 \mathrm{~nm})$ by original tequilas, ethanol, ethanol-water mixtures, methanol, and counterfeit tequilas obtained in Mexico City. The fluorescence excited at wavelengths of 365 and $405 \mathrm{~nm}$ is much more intense for original mixed, aged, and rested tequilas. Nevertheless, it can be visually detected in all the studied samples. That could be used to detect counterfeit tequilas.

\section{Materials and Methods}

2.1. Samples. Samples (from different bottles) of aged, rested, and silver authentic "100\% agave" tequila were used in this study. The number of samples $(n)$ for each of these tequilas was equal to 10. Also, samples of mixed tequila $(n=5)$, counterfeit tequila (whose color is similar to the authentic aged, rested, and mixed tequila) sold in the informal Mexican market $(n=5)$, chemical grade ethanol, methanol, and distillated water were analyzed as part of the present work.

2.2. Instrumentation. A portable homemade system was used to acquire fluorescence and transmittance spectra from the studied samples. The system comprises five major components: a light source, a fiber-optic probe, a spectrometer, a cuvette holder with four light ports, and a laptop or a PC. The system is depicted in Figure 1. For all measurements, four LEDs emitting at $255 \mathrm{~nm}$ (UVTOP255, SETi), $330 \mathrm{~nm}$ (UVTOP330, SETi), $365 \mathrm{~nm}$ (NCSU033A(T), Nichia), and $405 \mathrm{~nm}$ (405-1WUE, Violed Int.), respectively, were used as light sources. Three premium-grade optical fibers (QP400-2SR) were employed; one of them coupled to a light source and 


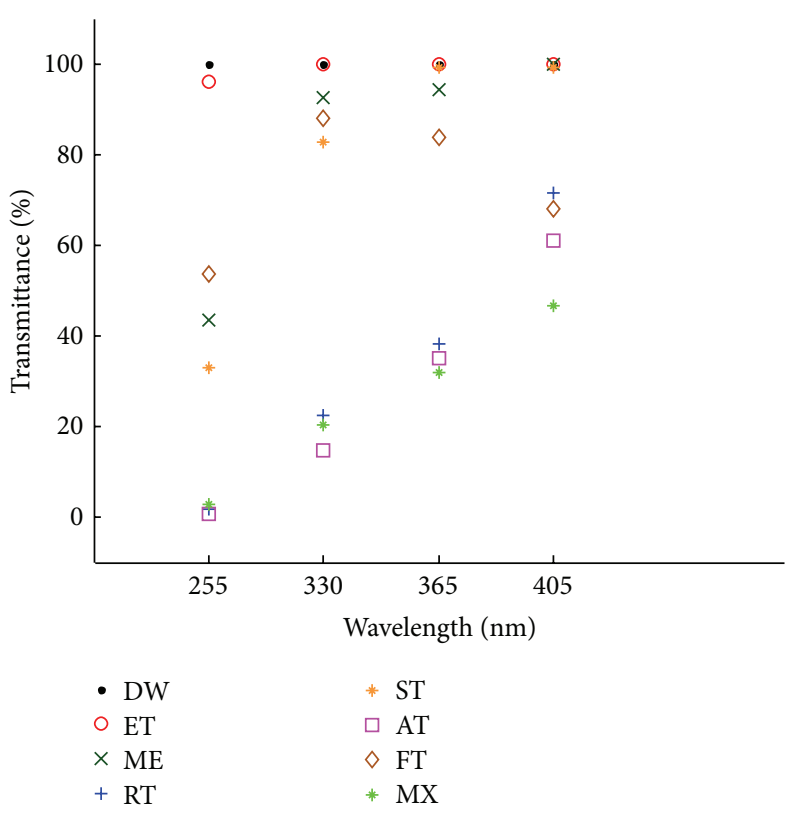

Figure 2: Transmittance of distilled water (DW), ethanol (ET), methanol (ME), aged tequila (AT), rested tequila (RT), mixed tequila (MX), silver tequila (ST), and a fake tequila (FT) at $255 \mathrm{~nm}, 330 \mathrm{~nm}, 365 \mathrm{~nm}$, and $405 \mathrm{~nm}$.

the others coupled directly to the spectrometer QE65000ABS for fluorescence measurements and to the ultravioletnear-infrared (UV-NIR) spectrometer HR4000CG-UV-NIR for transmittance measurements, respectively. The QE65000ABS spectrometer has a spectral range from 200 to $950 \mathrm{~nm}$ and $2 \mathrm{~nm}$ of resolution, whereas the HR4000CG-UV-NIR has a spectral range from 200 to $1100 \mathrm{~nm}$ and $0.5 \mathrm{~nm}$ of resolution. The samples were placed in $45 \times 12.5 \times 12.5 \mathrm{~mm}$ quartz cuvettes with transmittance range $190 \mathrm{~nm}-2.5 \mu \mathrm{m}$ (QS-204, Innovative Lab Supply). The spectrometers and the light sources were operated through a computer software program developed in National Instruments LabVIEW 2012.

\section{Results}

The transmittance average values (from the $n$ analyzed samples) for distilled water (DW), ethanol (ET), methanol (ME), aged tequila (AT), rested tequila (RT), mixed tequila (MX), silver tequila (ST), and fake tequila (FT) at the different peak emission wavelengths $(255 \mathrm{~nm}, 330 \mathrm{~nm}, 365 \mathrm{~nm}$, and $405 \mathrm{~nm})$ are presented in Figure 2. The distilled water and ethanol show very little absorption at the used wavelength range. Meanwhile, methanol shows a slight transmittance decrease with wavelength shortening up to $330 \mathrm{~nm}$; afterwards, a significant absorption can be noted for $255 \mathrm{~nm}$. The fake tequila is the only sample that shows a nonmonotonous dependence of the transmittance with the wavelength, as it was reported in [11]. The FT shows a maximal transmittance at $330 \mathrm{~nm}$, as it is reported in [15]. This behavior produces a change in the transmittance order of samples. For $255 \mathrm{~nm}$ the transmittance grows up in the order AT, RT, MX, ST, ME, FT, $\mathrm{ET}$, and DW. For $330 \mathrm{~nm}$, the transmittance grows up in the order AT, MX, RT, ST, FT, ME, ET, and DW (being almost $100 \%$ for ET and DW). At 365 the order is MX, AT, RT, FT,
ME, ST, ET, and DW (being almost $100 \%$ for ST, ET, and DW). At $405 \mathrm{~nm}$ the order is MX, AT, FT, RT, ME, ST, ET, and DW (being almost 100\% for ME, ST, ET, and DW). From Figure 2, it can be concluded that the linear behavior of the transmittance (lower than 40\%) from 255 to $365 \mathrm{~nm}$ could be a characteristic to discriminate MX, RT, and AT from the other samples. Also, a transmittance above $80 \%$ at 330 and $365 \mathrm{~nm}$ is characteristic of DW, ET, ME, ST, and FT.

The fluorescence of all samples detected at $90^{\circ}$ at different excitation wavelengths is presented in Figure 3. Each of these spectra is representative of all the measured samples for each analyzed substance. At $255 \mathrm{~nm}$, the fluorescence spectra presented in Figure 3(a) show distinctive features for each of the measured samples, except for the AT, RT, and MX, which have very similar spectra. This fact is most evident in the rightmost graph of Figure 3(a), where a zoom of the spectra shown in the left graph is presented. This indicates that a simple analysis of fluorescent spectra excited at $255 \mathrm{~nm}$ is a quite sensitive method to differentiate the genuine tequilas from adulterated and fake tequilas. From Figure 3(a), it is also evident that the methanol fluorescent spectrum presents a characteristic high peak at around $300 \mathrm{~nm}$.

At 330,365 , and $405 \mathrm{~nm}$ excitation wavelengths, the fluorescence spectra, presented in Figures 3(b), 3(c), and 3(d), respectively, show similar behaviors. The main differences between the spectra corresponding to the same sample reside in the different observed fluorescence intensity levels and also in the slight variation of the wavelengths for peaks at maximum fluorescent emission. However, in all the cases, the AT, RT, and MX spectra show the highest fluorescence emission. It is also evident that the ME sample fluoresces in a lesser degree than the AT, RT, and MX tequilas. On the other hand, ST and FT tequilas show a very similar fluorescence behavior at these three excitations wavelengths, 


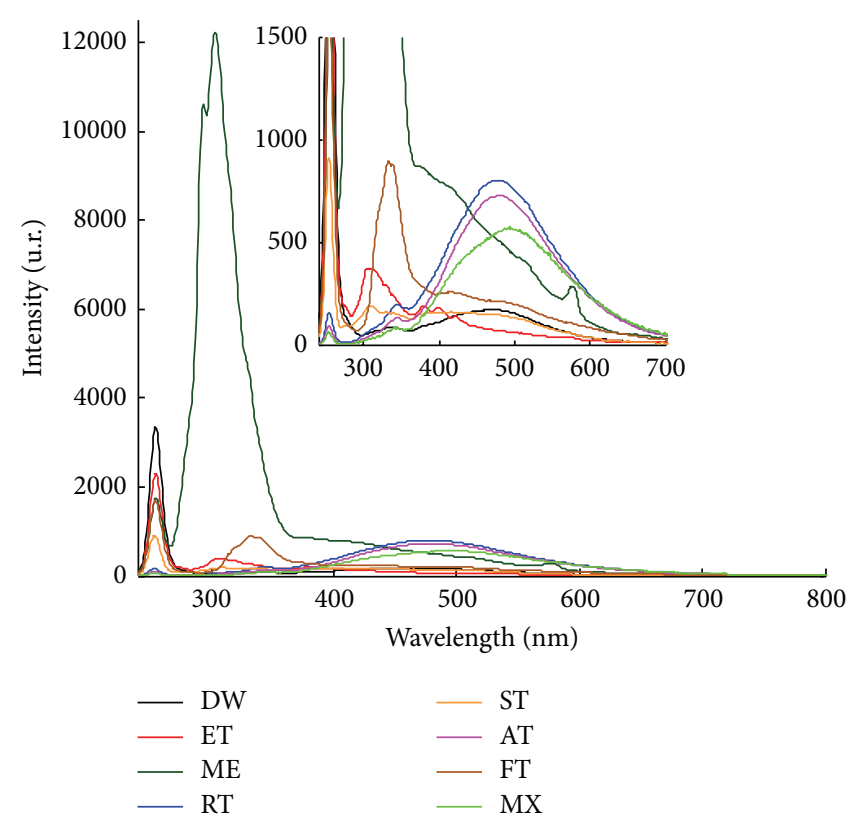

(a)

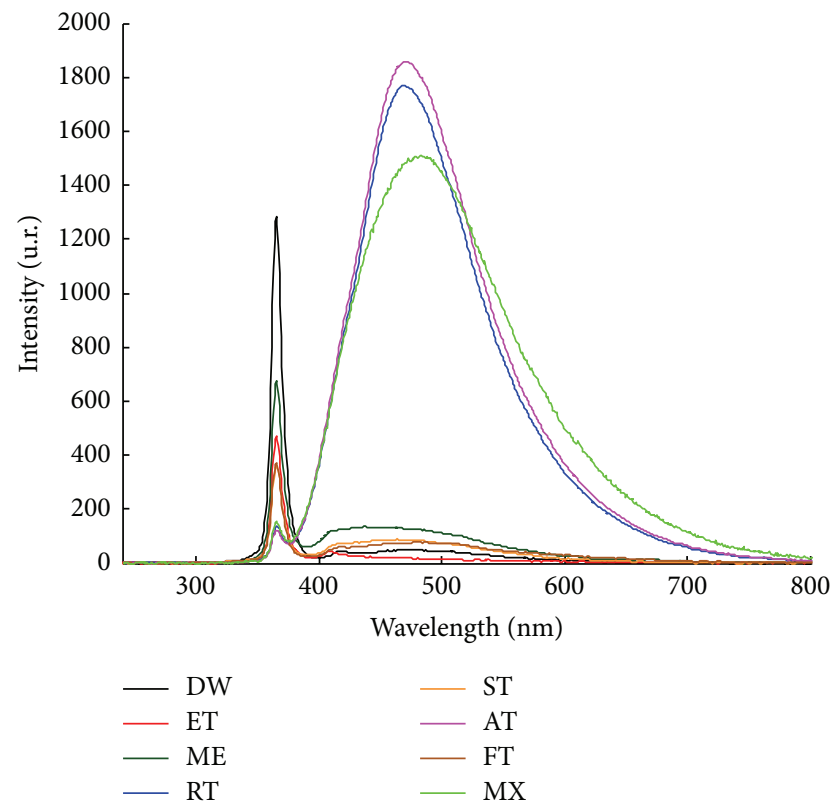

(c)

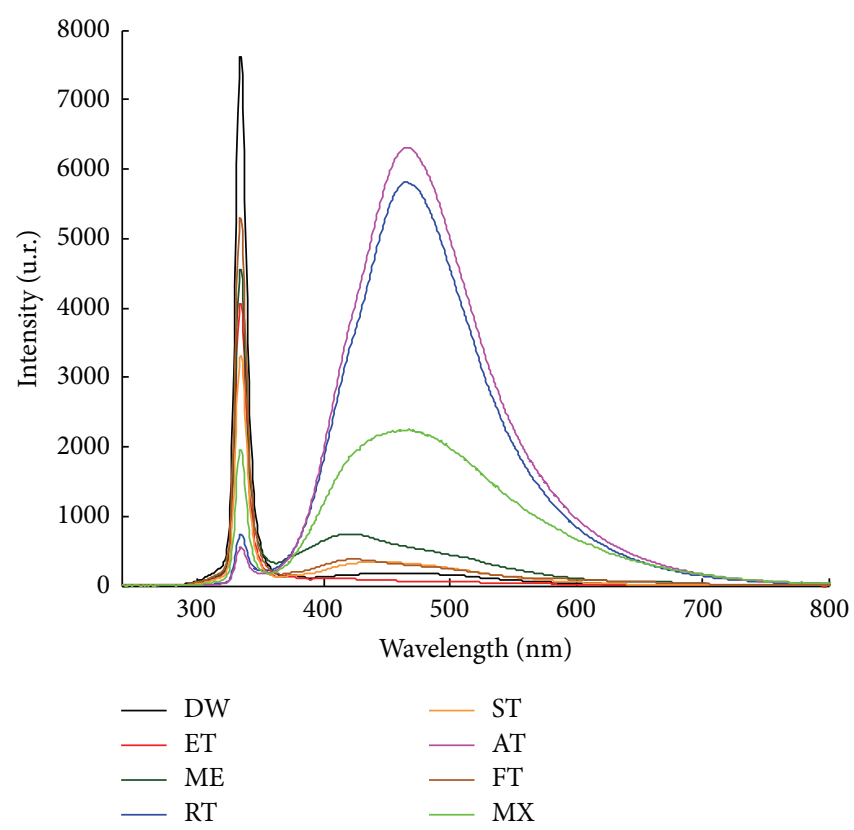

(b)

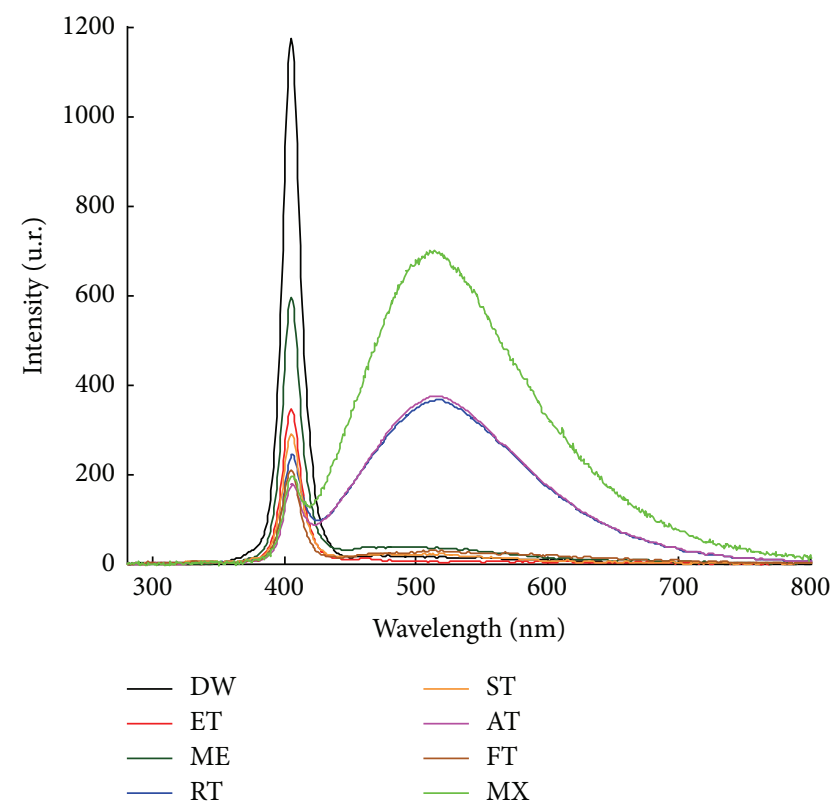

(d)

FIGURE 3: Fluorescence spectra of the studied samples at excitation wavelengths (a) $255 \mathrm{~nm}$, (b) $330 \mathrm{~nm}$, (c) $365 \mathrm{~nm}$, and (d) $405 \mathrm{~nm}$.

but their fluorescent intensity is considerably lower than those for the AT, RT, and MX tequilas. Figures 3(b), 3(c), and 3(d) also show that the maximal fluorescence to scattered excitation light ratio takes place at $365 \mathrm{~nm}$ of excitation. From Figure 3(d) it can be concluded that at $405 \mathrm{~nm}$ the fluorescence intensities are still considerable, even for ST and FT tequilas, as well as for ET and ME, though the aforementioned intensity differences are undoubtedly present. Thus, it can be expected that these differences can be detected with the naked eye. The confirmation to this behavior is shown in the photograph of Figure 4, where a $5 \mathrm{~mW}$ laser pointer, emitting at a wavelength of $405 \mathrm{~nm}$, has been used to pass the light through four glass bottles containing RT, FT, ET, and ME in that order from left to right. Independently of the absorption processes, it can be concluded that the genuine rested tequila (RT) exhibits the higher fluorescence compared with the faked counterparts.

The principal chemical components in tequila are ET and water. Therefore, the fluorescence spectra of fake tequila and of ET-DW mixtures in three distinct proportions (40$60 \%, 50-50 \%$, and $60-40 \%$ ) were measured using excitation wavelengths of 255, 330, 365, and $405 \mathrm{~nm}$. In Figure 5, these 


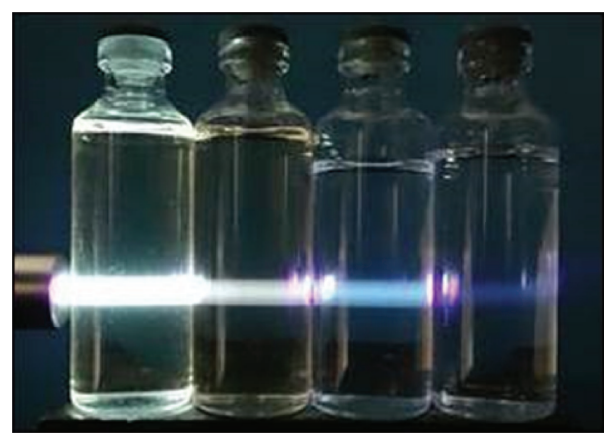

Figure 4: Visual fluorescence from RT, FT, ET, and ME (from the left to the right) excited with $5 \mathrm{~mW}$ at $405 \mathrm{~nm}$ of laser light.
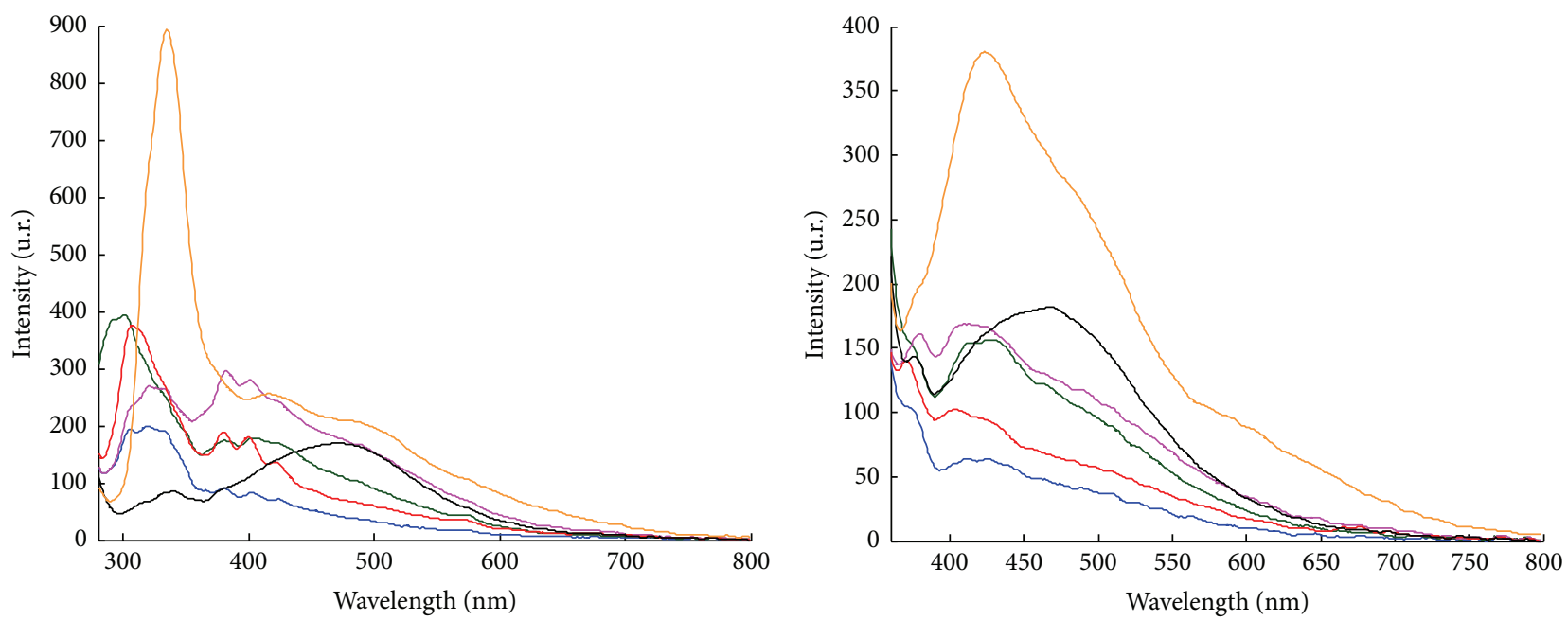

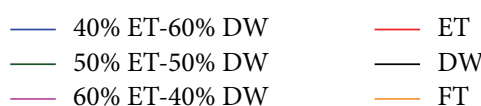

(a)

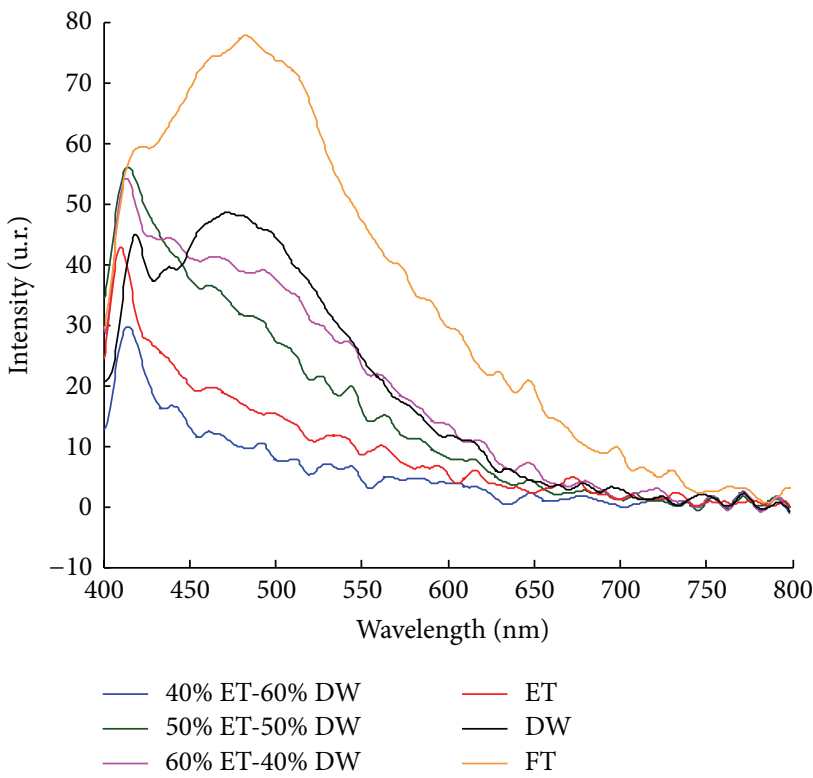

(c)

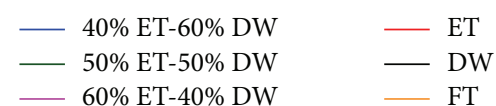

(b)

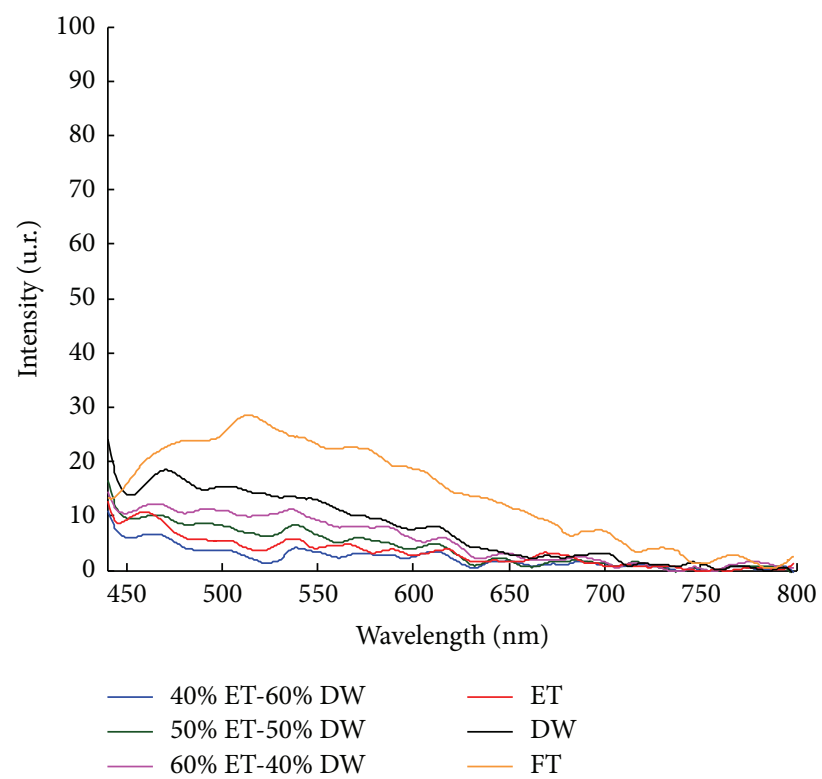

(d)

FiguRE 5: Fake tequila fluorescence (FT) compared to ethanol and distilled water mixtures fluorescence at different excitation wavelengths. (a) $255 \mathrm{~nm}$, (b) $330 \mathrm{~nm}$, (c) $365 \mathrm{~nm}$, and (d) $405 \mathrm{~nm}$. 


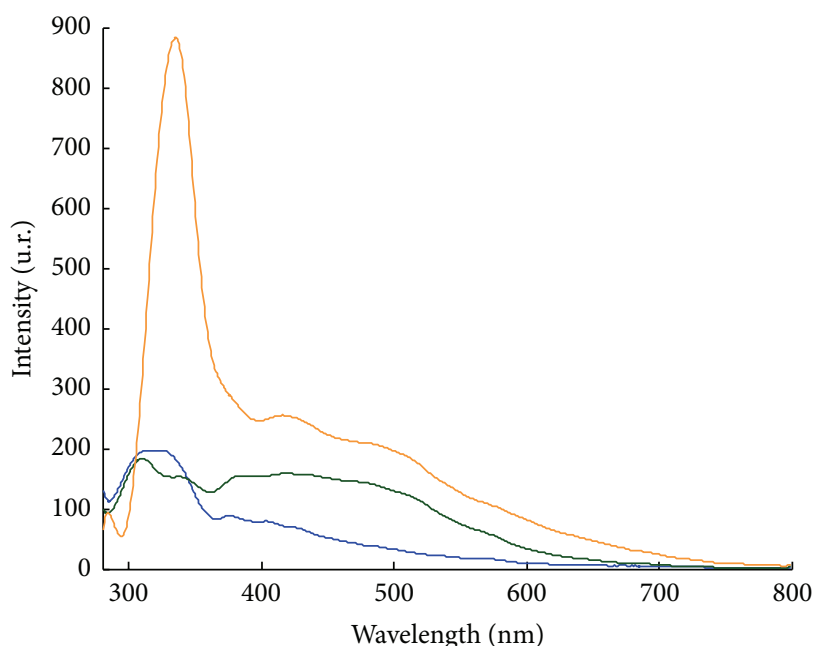

- $40 \%$ ET- $60 \%$ DW

- ST

- FT

(a)

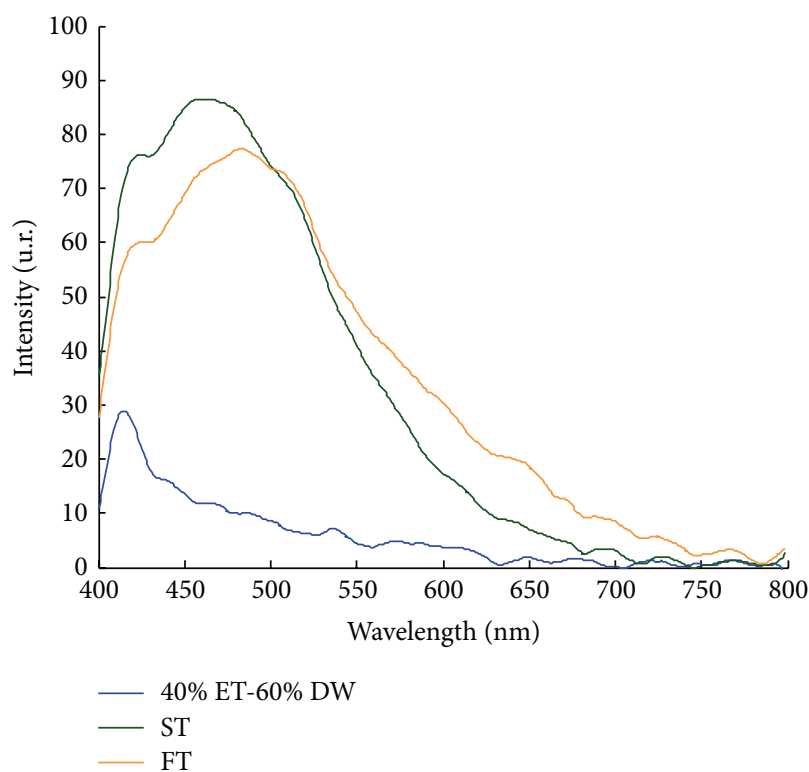

(c)

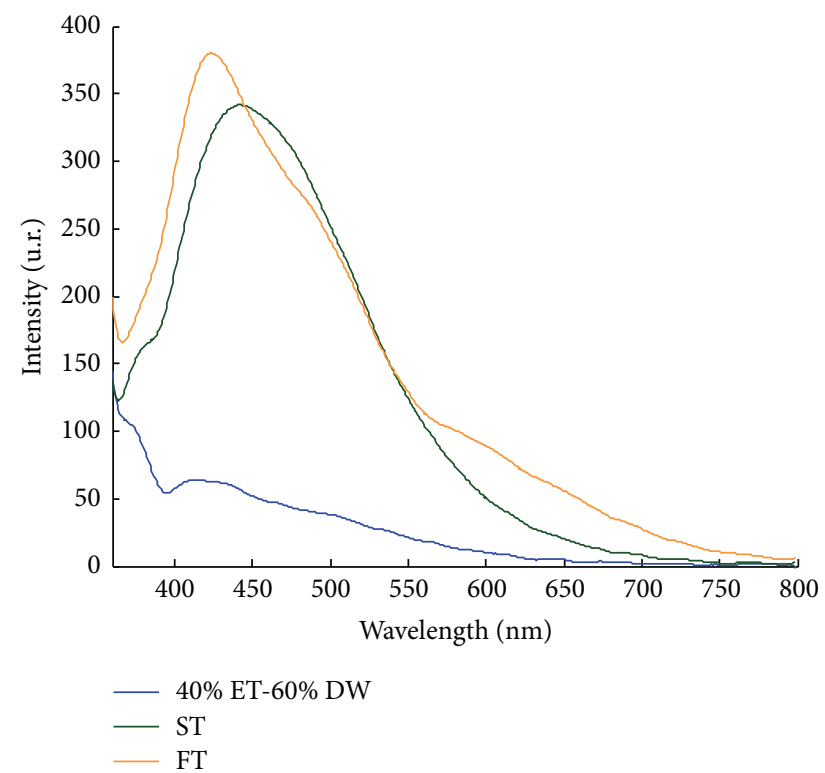

(b)

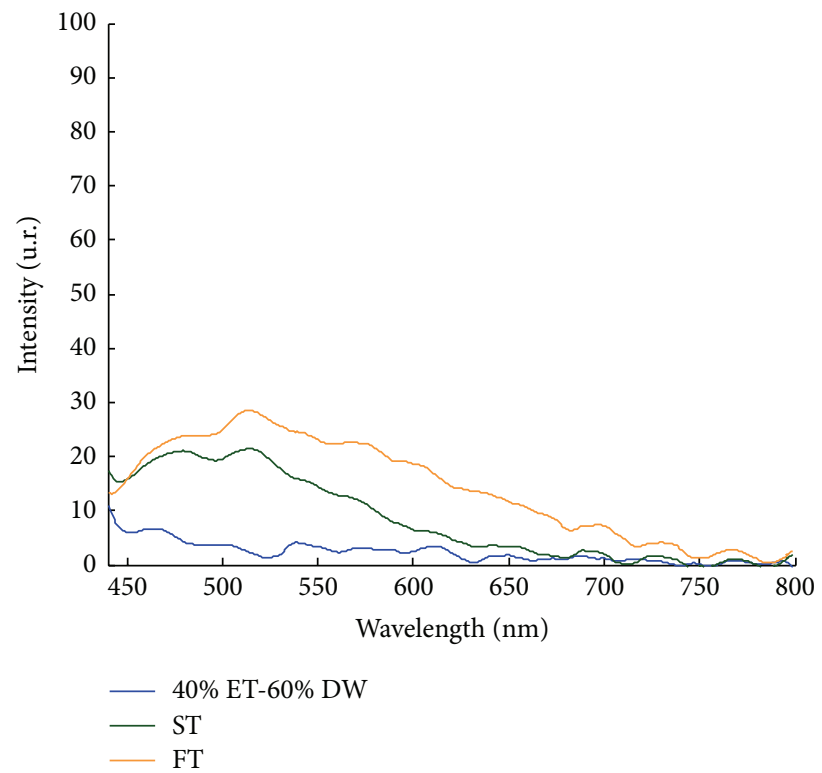

(d)

FIGURE 6: Fake tequila fluorescence (FT) compared to ET-DW (40\%-60\%) and ST fluorescence at different wavelengths. (a) $255 \mathrm{~nm}$, (b) $330 \mathrm{~nm}$, (c) $365 \mathrm{~nm}$, and (d) $405 \mathrm{~nm}$.

fluorescence spectra are compared. Figure 5(a) shows the spectral patterns obtained using an excitation wavelength of $255 \mathrm{~nm}$. There, differences in the spectra for different ET-DW ratios are observed, with a maximal fluorescence intensity around $400 \mathrm{~nm}$ for the $60 \%$ ET- $40 \%$ DW sample, reported elsewhere at the 240 to $480 \mathrm{~nm}$ interval [13].

From Figure 5 it is also apparent that the FT fluorescence is always higher than those of the ET-DW mixtures for every used excitation wavelength.
As the permitted alcohol content of tequila lies between 35 and 55\% [6], in Figure 6 the FT tequila, ET-DW (40\%$60 \%)$ mixture, and ST tequila fluorescence spectra are compared at different excitation wavelengths. At $255 \mathrm{~nm}$, the fluorescence spectra of all the samples show clear differences (see Figure 6(a)). However, at 330, 365, and $405 \mathrm{~nm}$ the fluorescence emissions from ST and FT are very similar, making it impossible to use these excitation wavelengths to discriminate between fake and silver tequilas. 


\section{Conclusions}

From the results it can be concluded that the fluorescence excited at $255 \mathrm{~nm}$ could be effectively used to discriminate adulterated and counterfeit tequilas from the genuine ones. Also, the detection method could be improved by a complementary measurement of spectral transmittance in the $255 \mathrm{~nm}$ to $405 \mathrm{~nm}$ wavelength interval. These results suggest the feasibility of building a compact and portable fluorescence spectroscopy system for a fast counterfeit tequila detection.

The fluorescence emission at 330, 365, and $405 \mathrm{~nm}$ from fake tequila and silver tequila cannot be used to discriminate the fake ones. On the other hand, aged, rested, and mixed tequilas can be discriminated from fake ones and from ethanol-water mixtures using 330, 365, and $405 \mathrm{~nm}$ excitation through spectrometric measurements or with naked eye observation of the visible fluorescence. Finally, the fluorescence of $100 \%$ agave tequila increases in the white-restedaged order; this could be useful to determine their maturation age.

\section{Conflict of Interests}

The authors declare that there is no conflict of interests regarding the publication of this paper.

\section{References}

[1] E. C. L. Nascimento, M. C. U. Araújo, and R. K. H. Galvão, "A flow-batch analyzer for UV-Vis spectrophotometric detection of adulteration in distilled spirits," Journal of the Brazilian Chemical Society, vol. 22, no. 6, pp. 1061-1067, 2011.

[2] Tequila Regulatory Council, https://www.crt.org.mx/.

[3] D. W. Lachenmeier, E.-M. Sohnius, R. Attig, and M. G. López, "Quantification of selected volatile constituents and anions in Mexican Agave spirits (Tequila, Mezcal, Sotol, Bacanora)," Journal of Agricultural and Food Chemistry, vol. 54, no. 11, pp. 3911-3915, 2006.

[4] J. Piggott, Ed., Alcoholic Beverages, Woodhead Publishing Limited, Philadelphia, Pa, USA, 2012.

[5] S. M. Benn and T. L. Peppard, "Characterization of tequila flavor by instrumental and sensory analysis," Journal of Agricultural and Food Chemistry, vol. 44, no. 2, pp. 557-566, 1996.

[6] Secretaría de Economía, "Bebidas alcoholicas-tequila-especificaciones," Norma Oficial Mexicana NOM-006-SCFI-2005, 2005.

[7] M. J. C. Pontes, S. R. B. Santos, M. C. U. Araújo et al., "Classification of distilled alcoholic beverages and verification of adulteration by near infrared spectrometry," Food Research International, vol. 39, no. 2, pp. 182-189, 2006.

[8] R. Nagarajan, R. Mehrotra, and M. M. Bajaj, "Quantitative analysis of methanol, an adulterant in alcoholic beverages, using attenuated total reflectance spectroscopy," Journal of Scientific \& Industrial Research, vol. 65, no. 5, pp. 416-419, 2006.

[9] B. O. Aguilar-Cisneros, M. G. López, E. Richling, F. Heckel, and P. Schreier, "Tequila authenticity assessment by headspace SPME-HRGC-IRMS analysis of ${ }^{13} \mathrm{C} /{ }^{12} \mathrm{C}$ and ${ }^{18} \mathrm{O} /{ }^{16} \mathrm{O}$ ratios of ethanol," Journal of Agricultural and Food Chemistry, vol. 50, no. 26, pp. 7520-7523, 2002.
[10] C. Bauer-Christoph, N. Christoph, B. O. Aguilar-Cisneros et al., "Authentication of tequila by gas chromatography and stable isotope ratio analyses," European Food Research and Technology, vol. 217, no. 5, pp. 438-443, 2003.

[11] O. Barbosa-García, G. Ramos-Ortíz, J. L. Maldonado et al., "UV-vis absorption spectroscopy and multivariate analysis as a method to discriminate tequila," Spectrochimica Acta A: Molecular and Biomolecular Spectroscopy, vol. 66, no. 1, pp. 129134, 2007.

[12] U. Contreras, O. Barbosa-García, J. L. Pichardo-Molina et al., "Screening method for identification of adulterate and fake tequilas by using UV-VIS spectroscopy and chemometrics," Food Research International, vol. 43, no. 10, pp. 2356-2362, 2010.

[13] A. Ronquillo, Detección de substancias a través de fluorescencia inducida por láser [M.S. thesis], SEPI-ESIME-IPN, 2007.

[14] J. Sádecká, J. Tóthová, and P. Májek, "Classification of brandies and wine distillates using front face fluorescence spectroscopy," Food Chemistry, vol. 117, no. 3, pp. 491-498, 2009.

[15] O. Barbosa García, G. Ramos Ortiz, J. L. Maldonado et al., "A quality control technique based on UV-VIS absorption spectroscopy for tequila distillery factories," in Fifth Symposium Optics in Industry, vol. 6046 of Proceedings of SPIE, Santiago de Querétaro, Mexico, September 2005. 

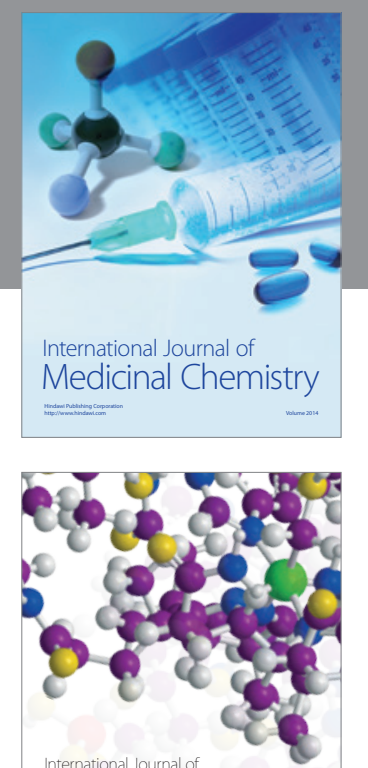

\section{Carbohydrate} Chemistry

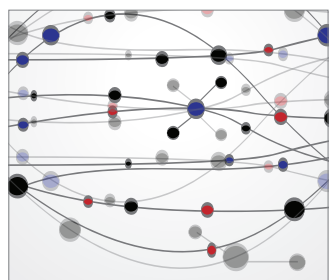

The Scientific World Journal
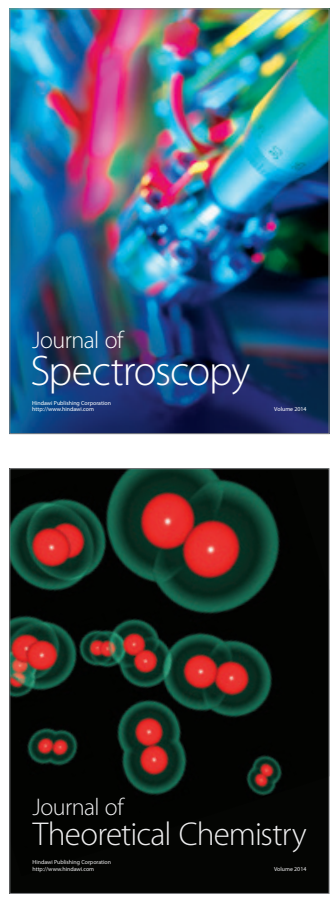
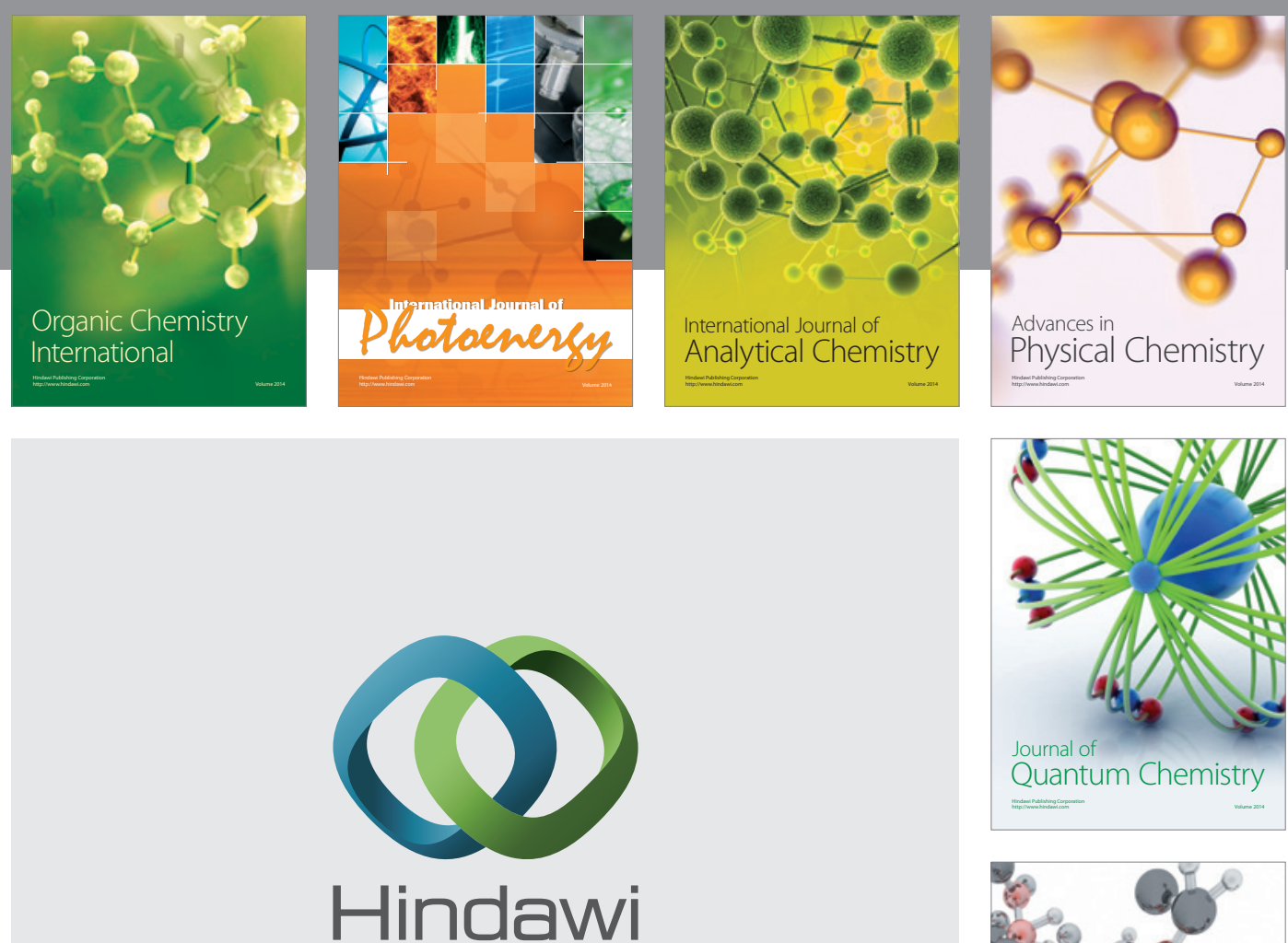

Submit your manuscripts at

http://www.hindawi.com

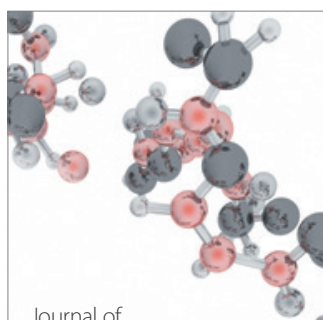

Analytical Methods

in Chemistry

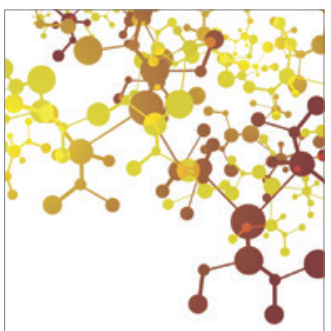

Journal of

Applied Chemistry

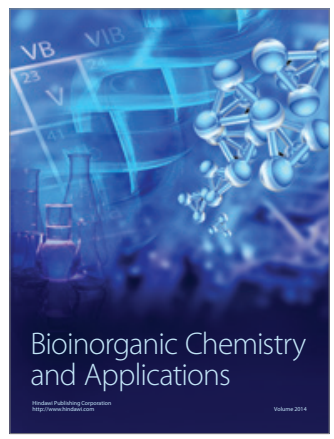

Inorganic Chemistry
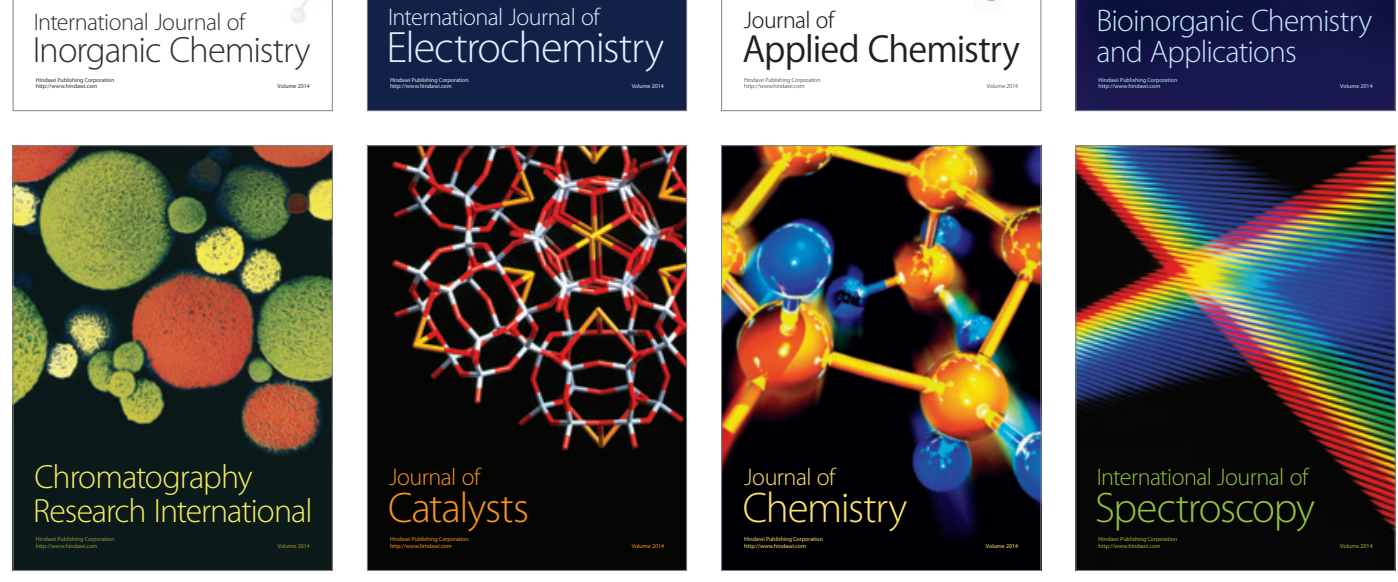